\title{
A Brain Capital Grand Strategy: toward economic reimagination
}

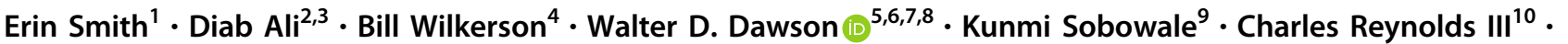 \\ Michael Berk ${ }^{11,12,13,14}$ - Helen Lavretsky ${ }^{9}$ - Dilip Jeste ${ }^{15}$. Chee H. $\mathrm{Ng}^{16}$ • Jair C. Soares ${ }^{17} \cdot$ Gowri Aragam $^{18}$. \\ Zoe Wainer ${ }^{19} \cdot$ Husseini K. Manji ${ }^{20,21} \cdot$ Julio Licinio ${ }^{22}$. Andrew W. Lo ${ }^{23}$. Eric Storch ${ }^{24}$ Ernestine Fu ${ }^{1}$. \\ Marion Leboyer ${ }^{25} \cdot$ loannis Tarnanas $\mathbb{C}^{7,8} \cdot$ Agustin Ibanez $\mathbb{D}^{7,8,26,27,28,29} \cdot$ Facundo Manes $^{27,30} \cdot$ Sarah Caddick $^{31}$. \\ Howard Fillit $^{32}$ - Ryan Abbott ${ }^{9,33}$ - Ian H. Robertson ${ }^{7,8,34}$ - Sandra B. Chapman ${ }^{34}$. Rhoda Au ${ }^{35}$ - Cara M. Altimus ${ }^{36}$. \\ William Hynes $^{37}$ - Patrick Brannelly ${ }^{38}$. Jeffrey Cummings ${ }^{39,40} \cdot$ Harris A. Eyre $\mathbb{I}^{11,12,18,41}$
}

Received: 16 July 2020 / Revised: 16 September 2020 / Accepted: 5 October 2020 / Published online: 26 October 2020

(c) Springer Nature Limited 2020

'I have not found among my possessions anything which I hold more dear than, or value so much as, my knowledge of the actions of great people, acquired by long experience in contemporary affairs, and a continual study of antiquity.' The Prince, Machiavelli

\section{The time is now for a Brain Capital Grand Strategy}

Current brain research, innovation, regulatory, and funding systems are artificially siloed, creating boundaries in our understanding of the brain based on constructs such as aging, mental health, and/or neurology, when these systems are all inextricably integral.

Grand strategy provides a broad framework that helps to guide all elements of a major, long-term project. There are converging global trends resulting from the COVID pandemic compelling a Brain Capital Grand Strategy: widespread appreciation of the rise in brain health issues (e.g., increase prevalence of mental illness and high rates of persons with age-related cognitive impairment contracting COVID), increased automation, job loss and underemployment, radical restructuring of health systems, rapid consumer adoption and acceptance of digital and remote solutions, and recognition of the need for economic reimagination. If we respond constructively to this crisis,

Harris A. Eyre

harris.eyre@gmail.com

Extended author information available on the last page of the article the COVID pandemic could catalyze institutional change and a better social contract.

Our current economy is indeed a Brain Economy-one where most new jobs demand cognitive, emotional, and social, not manual, skills, and where innovation is a tangible "deliverable" of employee productivity. With increased automation, our global economy increasingly places a premium on cerebral, brain-based skills that make us human, such as self-control, emotional intelligence, creativity, compassion, altruism, systems thinking, collective intelligence, and cognitive flexibility [1]. Investments in brain health and brain skills are critical for post-COVID economic renewal, reimagination, and long-term economic resilience.

Broadly, brain health encompasses emotional, behavioral, and cognitive strengths across the life span. Compromised brain health greatly increases the risk of disorders across the life span (e.g., depression, anxiety, substance misuse, dementias, and neurocognitive disorders) and hinders the achievement of each individual's full human potential. The concept of Brain Capital encompasses both brain health and brain skills as contributors to this Brain Economy. A Brain Capital Grand Strategy is urgently needed. Such a plan would be a first-ever strategic alignment across diverse public and private entities to structure and track investments that protect brain health and produce brain skills.

This paper discusses the parameters of this Grand Strategy including: a Brain Capital Investment Plan, examination of Brain Capital from an in-all-policies approach, and a Brain Capital Index. Underlying such efforts is the notion that Brain Capital can amplify existing recovery and growth efforts while helping to build longterm global economic capacity that promotes an equitable 
and sustainable brain health future. We recommend establishing an action taskforce comprised of local, state, federal, and global leaders in these key areas to further advance this work.

\section{The brain, our interconnected economy and COVID}

A recent Organization for Economic Co-operation and Development (OECD) Policy Response to COVID noted the global economy relies on complex, nested, interconnected systems to deliver goods and services [2]. COVID has highlighted that the systems we rely on in our daily lives (e.g., international supply chains) are vulnerable to sudden and unexpected disruption beyond our control. Economic systems need the ability to anticipate, absorb, recover, and adapt to unexpected threats [2]. COVID has clearly highlighted a lack of resilience within our global economic systems and an economic depression or recession is likely. A systems approach is critical to prepare the global interconnected socioeconomic systems for future impacts to reduce the shock. The McKinsey Global Institute recently published a report noting how investing in public health could accelerate post-COVID economic recovery [3]. While we agree with this conclusion, we note brain health is an overlooked, yet critical consideration in the systems approach to boosting economic resilience.

Psychological resilience is also a key to absorbing and adapting to social and economic shocks. Brain health disorders account for $>$ US $\$ 3$ trillion of lost productivity every year [4]. Brain health disorders have a global reach impacting every human either directly or indirectly. In COVID and similar pandemics, due to social and physical distancing, unemployment and underemployment, stress, and other factors, there have been significant increases in issues such as depression, anxiety, social isolation, substance abuse, loneliness, and cognitive decline in older adults [5-12]. In addition, as observed after the SARS pandemic, it is expected that COVID survivors may endure long term cognitive and psychiatric consequences, including suicide, post-traumatic stress disorders and depression [13]. The COVID pandemic can be regarded as a brain health catastrophe.

\section{The Brain Economy}

The modern global Brain Economy puts a premium on individual brain skills, but even more importantly, it demands the networking of individual brains to communicate and work together; this requires social intelligence resting on interpersonal skills and social perception and related abilities. The jobs of the future, for which we must prepare today, will increasingly value an individual's cognitive, emotional, and social brain resources. This is particularly important given that pressures on present-day jobs will emerge through the vast infusion of artificial intelligence and robots into workplaces and economies around the world requiring new workplace and brain function skills [14]. Furthermore, there are concerns about the developing brain (the workforce of the future) during the COVID pandemic; experts note reduced face-to-face contact among teenagers and their friends during the pandemic that could have damaging long-term consequences [8]. Moreover, cooperation and prosocial ability can be strong force for resilience and better societal responses [15]. Thus, this is a critical time to affirm the primacy of human and brain capital - that is, people - in the twenty-first century workplace and at both the production and consumption ends of the economy. The Brain Capital model demands a platform for a Brain Capital Investment Plan to stimulate and guide the massive pivot to allow the economic recovery and renewal that must emerge from the economic wreckage of COVID. The Brain Capital model provides a platform to consider this restructuring.

\section{The origins of Brain Capital}

The concept of Brain Capital was first articulated in 2011 by the Canadian-led Global Business and Economic Roundtable on Addiction and Mental Health [16]. Its core aim is to drive innovation in a Brain Economy by optimizing employee brain health and performance. Broadly, any objective working toward strengthening the global economy must focus on building and sustaining productive capacity by stimulating investments in brain health research, education, prevention, and care. Brain capital can be developed, strengthened, and empowered, as well as deteriorate or be impoverished depending on the stimulation and dynamics between the person and the social context. How a nation develops and uses its brain capital and well-being has a significant effect not only on its economic competitiveness and prosperity but on social cohesion and inclusion [15]. The Brain Capital model encourages employers to cultivate the cognitive capacity of their employees by optimizing employee brain health and emphasizes an international partnership of business and science to develop actionable brain health care [16].

Brain Capital was originally conceptualized to break down siloes between academia and the business sector recognizing that the reductionistic approach to mental illness has largely failed, and that the brain is an embodied organ within biological, social, cultural, ecological, and economic contexts [17-20]. The brain is best understood by 
transdisciplinary thinking, which seeks to integrate perspectives from genes, environment, culture, brain, body, mind, and economics [21].

\section{Our Brain Capital Grand Strategy}

The immediate economic lesson of COVID is that we need a clearly articulated action plan that extends and expands the existing Brain Capital model. We propose that this plan synergistically integrates the following components:

(1) Insights from human-, psychological-, social-, and cognitive capital, and neuroscience-based policy.

(2) The fundamentals of a Brain Capital Investment Plan.

(3) An in-all-policies or holistic policy approach.

(4) A Brain Capital Index and other ways of tracking, benchmarking, and implementing this agenda.

\section{Foundational disciplines informing the development of Brain Capital}

As noted above, at the core of expanding the Brain Capital model is the need to incorporate insights from existing established and interrelated models such as human-, mental-, psychological-, social-, and cognitive capital, and neuroscience-based policy [22-26].

Human capital is characterized as the aggregate levels of education, training, skills, and health in a population that, in turn, affects the rate at which technologies can be developed, adopted, and employed to increase productivity. In response to the current massive underinvestment in the potential of human capital and its central role in the digital economy, the World Bank recently introduced its Human Capital Project. The project seeks to "understand the link between investing in people and economic growth, and to accelerate financing for human capital investments" [27]. Monitoring the generation and investment in human capital facilitates a mechanism to hold governments and donors accountable for investments in health and education $[23,28]$. Currently, there is a relative paucity of investments in health- and education-related drivers of human capital; for instance, only $1.5 \%$ of the World Bank International Development Association concessional grants are for health and only $1.9 \%$ for education. In contrast, a much greater "balance sheet" focus exists for "tangible" physical capital such as buildings and equipment - a holdover industrial-age policy ill-suited for the information age [23]. This underinvestment in human capital is typical of the chronic underinvestment in brain health research and care [29].
Brain Capital can use context and insights drawn from social capital, largely defined as an individual's social relationships and participation in civic and community networks that enables society to function successfully. Social capital can be understood as an inherent cohesive force that enables collective action within populations. With regards to mental disorders, social capital may lower risk while increasing intellectual cross-pollination, resilience capacity, successful adaptation, emotional intelligence, cooperation, and recovery [24, 30, 31]. Interventions to enhance social capital may be a cost-effective way of preventing and ameliorating mental health conditions while augmenting social and brain capital; sample interventions include community engagement and educative programs, and evidence-based forms of psychological treatment (e.g., cognitive processing therapy and sociotherapy for trauma survivors) [24]. However, the degree to which social capital interventions impact brain health requires further validation. One long-standing deficit of social capital is the inadequate attention to the power inequalities that drive poor health, often linked to macro-social and economic forces beyond the reach of local community activism. Attention to social movement participation has begun to address this [32].

Psychological capital draws from positive psychology concepts in general and from positive organizational behavior in particular $[25,26]$. It describes how an individual's psychological capacity can be developed and managed for performance improvement [33]. Psychological capital comprises "(1) hope: persevering toward goals and when necessary, redirecting paths to goals in order to succeed; (2) self-efficacy: having confidence to succeed at challenging tasks; (3) optimism: making a positive attribution regarding succeeding now and in the future; (4) resilience: when beset by problems and adversity, sustaining and bouncing back and even beyond to attain success" [26].

Human cognitive capital is a dynamic rather than fixed capacity that has been defined as an "accumulating asset that can be drawn upon to create and to take advantage of opportunities and to sustain well-being, in response to environmental challenge and stress" [34]. Chapman et al. [35] propose there is potential to harness the brain's innate neuroplastic abilities to optimize human performance and to strengthen human cognitive capital simultaneously, by engaging and enhancing function across their five pillars of brain health, namely, neural systems, top-down cognitive control processes, psychological well-being and quality of life, real-life performance, and social agility.

Finally, neuroscience-based public health policies such as early childhood support, nutrition, quality education, jobs, and skills-training are critical to productivity, flourishing, and brain health [22, 36, 37]. Key findings and advances in neuroscience hold overt potential to improve public policy. For example, early child care and early intervention in 
education could reduce crime, encourage creativity and community contributions, improve educational outcomes and productivity in work, and reduce pressure on health and care systems by preserving mental capital across the age spectrum [22]. Anti-poverty programs based on scientific evidence about brain health could similarly improve the Brain Capital of people living in poverty [38]. Neuroscience research across the human life span (ranging from infant development to older age) could be incorporated into public policy, providing the opportunity for a cross-governmental approach that places brain capital and well-being at the heart of policymaking $[22,38]$.

\section{Formalizing Brain Capital}

Under our novel formulation, the concept of Brain Capital would encompass the knowledge, creative skills, and optimized brain health that people accumulate and can strengthen throughout their lives that enables them to realize their potential as productive members of society. Brain Capital should be supported at all levels of policymaking to ensure impact on human functionality and productivity (Fig. 1). Brain Capital goes beyond reducing and treating mental illness and embraces the development of creativity, positive psychology, and innovation to create a better world.

\section{Proposing a Brain Capital Investment Plan}

A range of existing initiatives further the goals of the Brain Capital Investment Plan and could be useful models for developing new programs in the future. Investment and innovation approaches, outlined in Table 1, include those in:

(1) Supporting health systems in the transition to Valuebased Health Care.

(2) Government grantmaking.

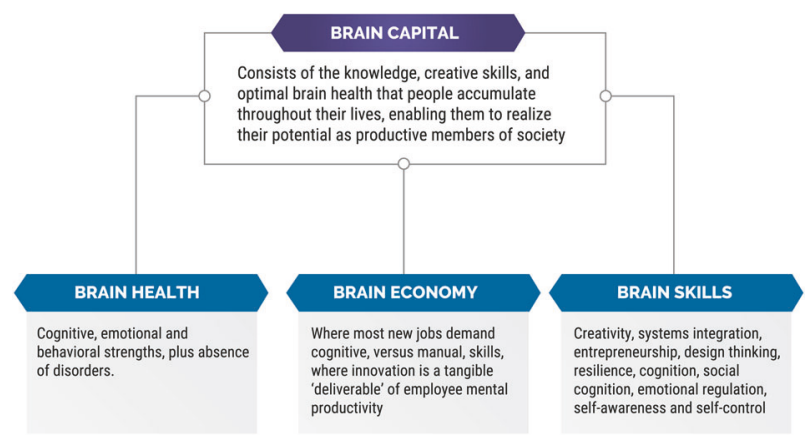

Fig. 1 Overview of the Brain Capital Model. This figure provides the definition of Brain Capital, as well as an explanation of sub-components of Brain Capital i.e. Brain Health, Brain Economy and Brain Skills.
(3) Social impact investing.

(4) Taxation and accounting restructuring to support Brain Capital.

(5) Information technology company investments (e.g., social media platforms, search engines, and consumer electronics companies).

(6) Established medical innovation company investments (e.g., pharma, biotech, and medical device).

(7) Early stage technologies.

(8) Megafunds for developing $\mathrm{AD}$ therapeutic innovations.

(9) Brain bonds [39] (e.g., Healthy Brains Global Initiative (HBGI)).

(10) Novel forms of corporate structuring (e.g., B Corps).

(11) Philanthropy.

\section{Initiatives aligned with the Brain Capital Investment Plan}

\section{The Weill Neurohub}

The Weill Neurohub brings together researchers and clinicians at three premier West Coast research institutions to speed the development of new treatments for neurological and psychiatric diseases [40]. By leveraging the unique strengths of the University of California, Berkeley, the University of California, San Francisco (UCSF), and the University of Washington, the network forges and nurtures collaborations between neuroscientists and researchers working in an array of disciplines-including engineering, computer sciences, physics, chemistry, and mathematicsand across institutions. Its researchers and clinicians have access to novel tools to break through established thinking and inspire powerful innovation for patients across the West and around the world. This collaborative effort is underpinned by unmatched computational power and device manufacturing at the Lawrence Livermore National Laboratory and the Lawrence Berkeley National Laboratory. The Weill Neurohub funds projects built on one or more of four scientific "pillars" deemed most likely to fuel the development of high-impact new approaches to neurological and psychiatric diseases: imaging, engineering, genomics and molecular therapies, and computation and data analytics. The Weill Neurohub prioritizes the growth of established and emerging, cross-campus, interdisciplinary interactions by supporting collaborative research projects with near-term transformational potential; seed-funding novel research ideas led by pioneering investigators; recruiting new talent to fill knowledge gaps; training the next generation of clinicians and scientists; and hosting symposia, retreats, and meetings to share knowledge, 


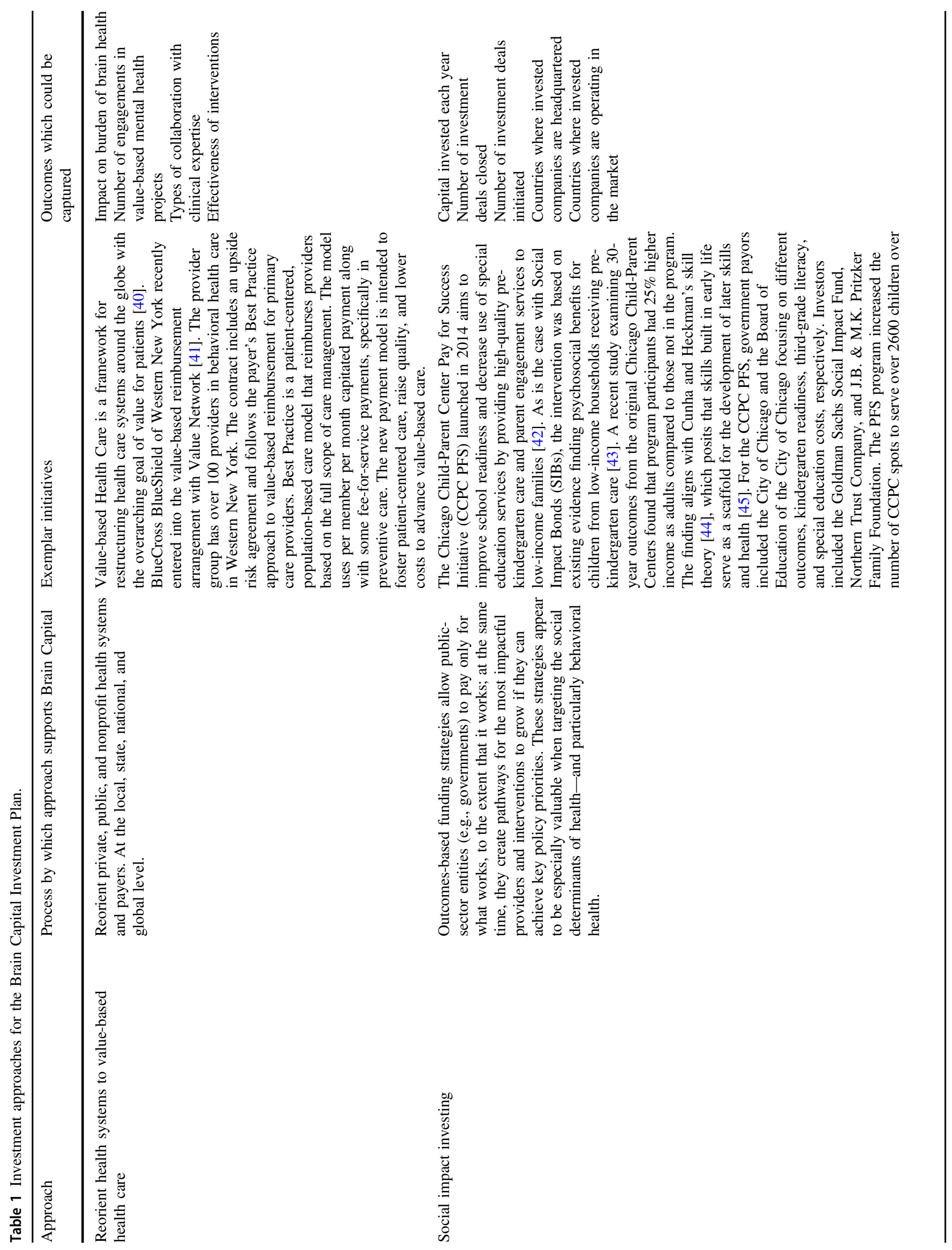




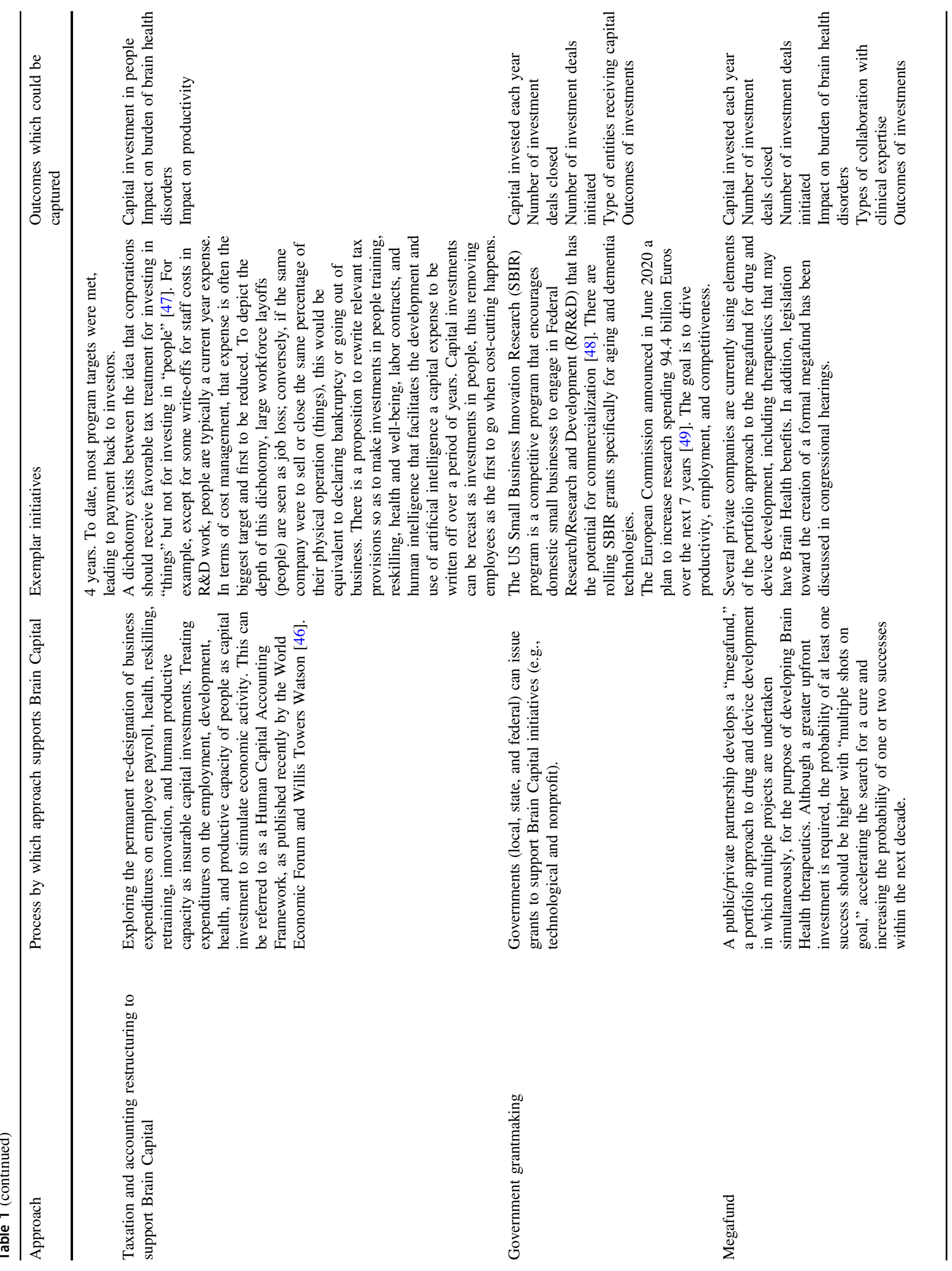




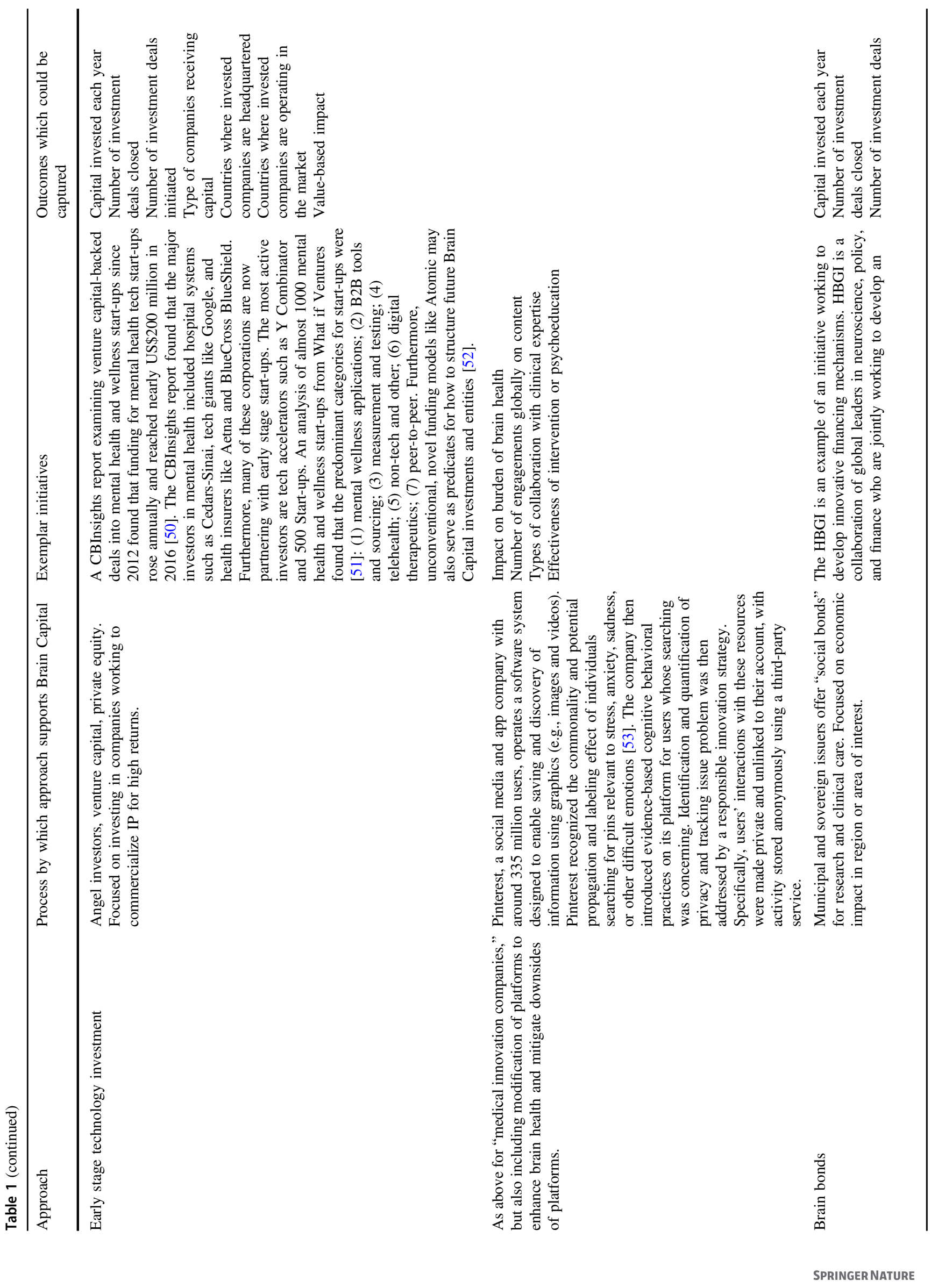




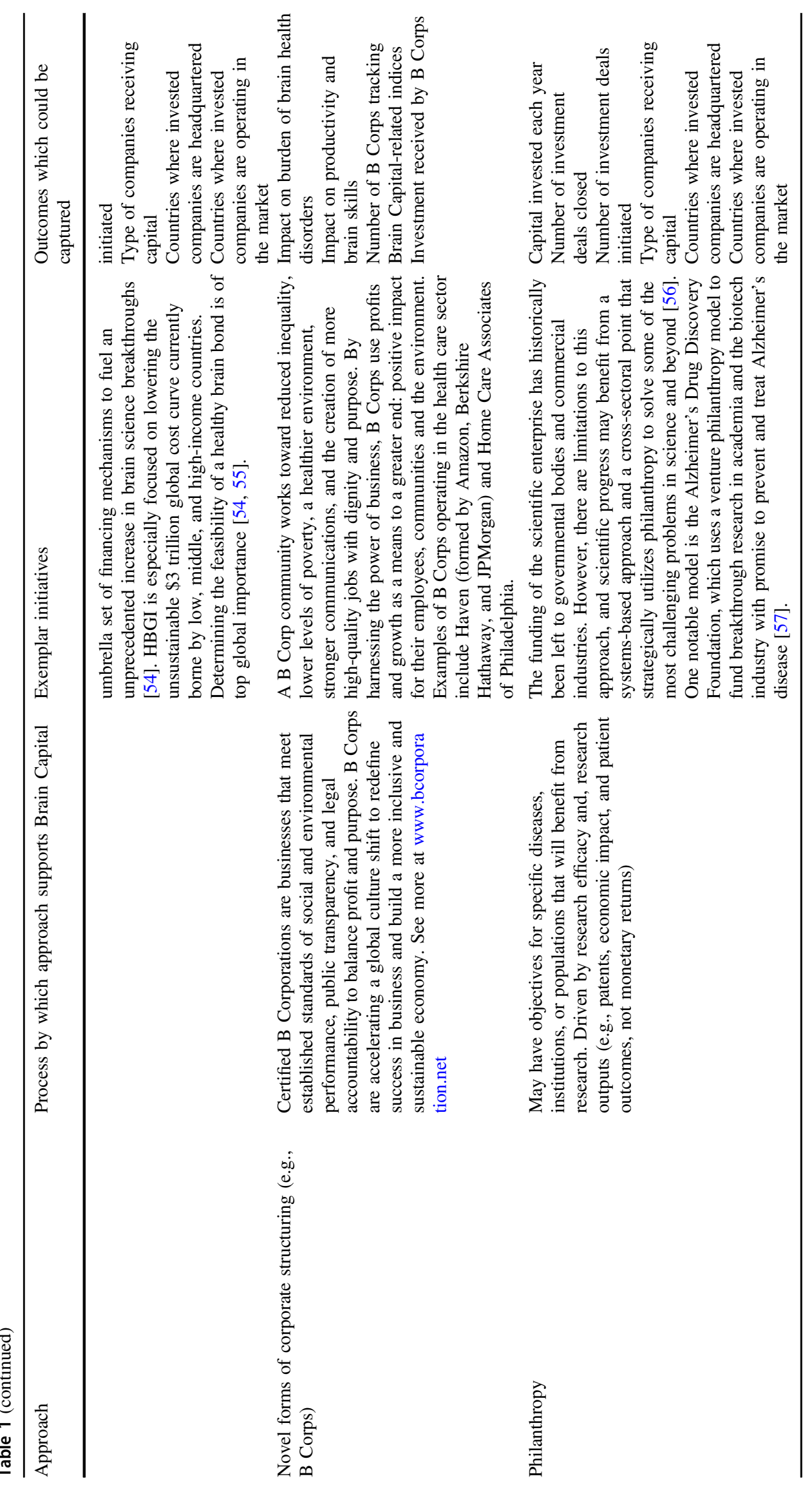


encourage new alliances, and inspire investigators and clinicians.

\section{Healthy Brains Global Initiative (HBGI)}

HBGI is developing $\$ 10$ billion of financing mechanisms to fund increased delivery of brain science breakthroughs and evidence-based interventions [41]. One Mind and the National Academy of Medicine are leading the HBGI in collaboration with the World Bank, the World Health Organization, the US National Institutes of Health, as well as leading investment banks, grant-making organizations, and research organizations. In the High-Income settings where HBGI capital may be deployed, the California's Stem Cell Agency (CIRM) provides a useful predicate for potential outcomes. CIRM aims to accelerate stem cell treatments for patients with unmet medical needs [42, 43]. A recent report found that CIRM has had a major impact on California's economy, creating tens of thousands of new jobs, and producing billions of dollars in additional tax revenue for the state-co-benefits to CIRM's main goal to improve health and well-being [42, 43].

\section{Behavioral Insight and Neuroscience Unit}

One group created the first Behavioral Insight and Neuroscience Unit for social protection and health policies in Latin America to foster improvements in the most critical life span stages: early childhood and aging [44]. This Behavioral Insight and Neuroscience Group offers innovative approaches to solve health and social problems (such as poverty and malnutrition) in Latin America. The same group, launched the "Mental Capital and Wellbeing Delivery Unit," in 2016, a social innovation agency in the Office of the Chief of Staff of the Province of Buenos Aires with experts from the fields of neuroscience, education, health, and social policy working to advise government in order to build a coalition to share best practices, promote evidence-based policies, and make this topic a priority for Argentina. Understanding the neuroscientific evidence on how to stimulate cognitive and socio-emotional skills among different type of populations is crucial to improve the design of government policies. Public policy interventions can focus on promoting these skills throughout life.

\section{Social Impact Bonds}

Pay-for-Success financing, often called Social Impact Bonds, is governmental pay-for-performance schemes that shift investment risk and metrics of success for interventions. Instead of governments providing funding, private investors provide upfront capital for a service provider to deliver an intervention and are repaid only if predetermined metrics of success are met [45]. In the state of Connecticut, for example, behavioral and mental health initiatives include psychological interventions such as cognitive behavioral therapy for incarcerated youth and substance use treatment and attachmentbased therapy for parents with substance misuse [46]. The demonstration called the Connecticut Family Stability Project illustrates the various stakeholders involved in a Social Impact Bond. Social Finance, an intermediary, assembled stakeholders including a group of private and nonprofit investors including BNP Paribas, QBE Insurance, the Laura and John Arnold Foundation, and the Doris Duke Charitable Foundation invested \$11.2 million. The service provider, Familybased Recovery Services (hosted at the Yale Child Center), provides clinical services to families. If the independent evaluator, UConn Health, finds that the predetermined outcomes of reduction in out-of-home placements, reduction in re-referrals to the Connecticut's child welfare agency (Connecticut Department of Children and Families), reduction in substance use, and successful enrollment in the family-based services are realized, the Connecticut Department of Children and Families will repay the investors their principal with interest. In Massachusetts and New York City, social interventions such as employment assistance to veterans with service-related post-traumatic stress disorder are conducted in conjunction with the Veterans Administration [46].

The Career Impact Bond (CIB) is a "pay-for-success" financing tool that provides students with affordable, highquality workforce training for in-demand careers. This is therefore an approach to optimizing "brain skills." CIBs have been developed a pioneered by Social Finance [47]. This Bond is a student-centered income-share agreement that expands access to high-quality, industry-recognized career training to people from low-income communities and those who face barriers to education and employment, such as criminal justice involvement, immigration status, or low levels of educational attainment or professional experience. With CIBs, impact investors provide catalytic capital to training providers, which use the funds to cover a portion of the upfront training costs and deliver critical support services for typically underserved students. Then students enroll free of charge, persist, and graduate. Those who gain meaningful employment repay program costs as a fixed percentage of their income, capped at a certain dollar amount and for a certain period of time. And those who do not obtain and maintain meaningful employment following graduation pay nothing. Impact investors and training providers share any payments received from students who find good jobs and achieve increased economic mobility. This model is now being trialed with General Assembly, an educational institution focused on teaching entrepreneurs and business professionals practical technology skills. Project supporters include the Wilmington Trust, Google.org, and Prudential Financial. The CIB model may reduce 
under- and unemployment and associated mental health issues, however, this requires empirical study.

\section{The BrainHealth Project}

The BrainHealth Project is a landmark scientific study that will redefine our understanding of brain health and our lifelong ability to impact its fitness [48]. The BrainHealth Project's bold goal is to achieve for brain health what has been accomplished for heart health-where every person knows steps to take to keep their brain working longer and stronger. The Project is the largest, longitudinal, and interventional endeavor to push new frontiers in the health of our brain. This initiative is led by the Center for BrainHealth, a cognitive neuroscience research and translational science institute of The University of Texas at Dallas. BrainHealth researchers and clinicians focus on discovering and translating scientific breakthroughs about the brain's capacity and potential to strengthen, endure, and work more efficiently. The Project is a large-scale scientific collaboration of scientists, educators, and business leaders. It seeks to: Define brain health: translate the science of neuroplasticity to embrace the upward potential of the human mind to extend cognitive capacity and innovative thinking, overcoming the outdated notion of fixed intelligence to reduce stigma and fear. Measure brain health: create a standardized BrainHealth Index ${ }^{\mathrm{TM}}$, a multifaceted measure comprised of cognitive, social, psychological well-being, real-life function, and neural domains, to characterize and track performance on personalized brain health fitness goals. Enhance/ Maintain/Regain brain health: offer evidence-based trainings, self-paced game-like activities, and quarterly coaching to help individuals stay motivated to continually take steps to improve and extend their brain health and performance.

\section{Brain Health Living Labs (BHLL)}

BHLL is a user-centered, iterative, open-innovation ecosystem, operating in a clinical-academic setting, integrating concurrent clinical care, research, and innovation processes within a public-private-consumer partnership. By leveraging the BHLL model, patients, caregivers, families, medical, allied and community health care workers, health coaches, technology innovators, engineers, entrepreneurs, researchers, and policymakers can collaborate and grapple with brain health challenges around the world within a connected community setting. BHLL-based collaboration should occur during the selection, integration, implementation, and evaluation of brain health tools and interventions based on evolving and emerging technologies. This lab model can be integrated into current brain health clinic infrastructure. We believe this diverse, inter- and transdisciplinary approach is critical and will yield many unanticipated improvements and advances, especially in developing the brain health clinic of the future [21]. Examples include: Cleveland Clinic's Brain Health Initiative (https://healthybrains.org/), The Oregon Center for Aging and Technology (https://www.ohsu.edu/oregoncenter-for-aging-and-technology), Integrated Network for Completely Assisted Senior Citizen's Autonomy, McLean Hospital Technology and Aging Lab, part of McLean's Institute for Technology in Psychiatry.

\section{Alzheimer's Drug Discovery Foundation (ADDF)}

Another notable model to fuel developments in brain health is the ADDF, which uses venture philanthropy to fund breakthrough research in academia and the biotech industry with promise for preventing and treating Alzheimer's disease and other dementias [49]. The ADDF partners across disciplines with governments, philanthropy, industry, and nonprofits such as the Bill \& Melinda Gates Foundation and the American Association of Retired Persons (AARP) to achieve this goal [50]. Any proceeds that accrue to the ADDF as a result of a program's success are then reinvested in additional research.

\section{Alzheimer's disease therapeutics megafund}

A bold proposal for the Brain Economy is a public/private partnership for a "megafund"- - a portfolio approach to drug and device development in which multiple projects are undertaken simultaneously, for the purpose of developing AD therapeutics [51, 52]. At the time of its first proposal in 2014, the high upfront costs and the simulated risk-reward profile of a pure Alzheimer's disease megafund were such that a private-sector-only effort was not financially compelling, despite the long-term costs of the disease and the importance of the Brain Economy. In recent years, however, the increase in public funding of early stage clinical brain research, including the BRAIN initiative and the growth in National Institutes of Health funding for Alzheimer's research from $\$ 600$ million in 2015 to a projected $\$ 2.8$ billion in 2020, has changed the scientific and investment landscape. In the portfolio, a larger number of early stage clinical projects will tend to decrease the correlation of success or failure between projects, which is a crucial determinant of the financial return to the megafund. The greater the scientific independence of each early stage project, the less likely it will be that one failure in therapeutic development will affect another, thus raising the overall probability of success and its contribution to Brain Capital in terms of scientific knowledge, therapeutic development, and investment return on capital. Given the high upfront cost estimates for a large AD portfolio (\$38 
Table 2 Brain Capital in all policies.

Policy area Opportunity with the Brain Capital Grand Strategy

Women's affairs

First nations people

Multiculturalism and immigration

Military and veterans

Industry and innovation

Foreign affairs and trade

Climate and environment

Health care

Social services

Aged care

Cybersecurity and misinformation

Transportation and infrastructure

Education
Globally, women's brain capital is massively unrecognized and underutilized. Funding research and innovation into the field of sex and gender differences in brain health prediction, disorders, diagnosis, treatment, and prevention are critical. There is an increasing understanding of the role of biology as well as social and cultural factors leading to underinvestment in women's brain capital. There is a recognition that clinically relevant insights need to be systematically incorporated into policy and care.

Address the factors recognized as contributing to current mental health challenges faced by first nations people. Taking a life span approach recognizes that mental health disadvantages start before birth; these include intergenerational trauma and barriers to accessing health services in pregnant women. A community mental health approach can help address the historical background factors that have led to increased mental health problems among first nations people.

Racial and ethnic minorities, refugees, asylum seekers, often suffer from poor mental health outcomes due to multiple factors; these include inaccessibility of high-quality mental health care services, cultural stigma surrounding mental health care, discrimination, and overall lack of awareness about mental health.

Develop greater accessibility to brain health resources, overcoming delivery barriers and stigma. Ensuring support for brain health and mental well-being at the top leadership level is especially important to prevent negative career effects for those who seek treatment. An opportunity also exists to develop preventative measures for post-traumatic stress, traumatic brain injury, dementia, and other conditions to which military personnel are susceptible and to successfully transition to civilian life. Consideration must be give not noncombatants in conflict zones, who are also at risk for trauma-related issues.

Preventative strategies can be developed to mitigate brain health effects from automation and potential job loss or displacement and the need for retention. Working to ensure people has productive coping strategies that can prevent anxiety and depression, boost brain capital across the lifetime, and reverse the health effects of prolonged stress. Innovations in the future of the workplace (e.g., reduced work hours, developing ways to be less sedentary with increasing automation, etc.) may also help develop brain capital. Assess the brain health value of universal basic income.

International diplomacy is needed that promotes brain capital and considers the brain health and brain skills implications of decisions, seeks synergies, and avoids harmful impacts. Brain health innovation diplomacy (BIND) seeks to improve global brain health via diplomacy, strengthen health systems, and leverage public and not-for-profit sectors, while also leveraging technological innovation, entrepreneurship, and innovation diplomacy to improve global brain health outcomes.

A pressing need exists to fund research into risks, impact, and priority actions of climate change and brain health. An overt opportunity exists to increase our understanding of the dynamics between the brain and environmental changes and to develop innovative solutions and strategies.

Innovation is increasingly valued within health care systems, particularly with recent emphasis on remote health care technology. Changing the paradigm from an acute care model to emphasize health promotion and primary prevention of chronic disorders linked to lifestyle choices (such as obesity, cancer, cardiovascular disease, and stroke) that are currently the main source of high cost of health care to the society. An opportunity exists to develop strategies to integrate mental and neurological disorders into primary health care to help achieve accessible, equitable, and universal health coverage. Current barriers need to be overcome by increasing funding, rethinking, and harmonizing the architecture of primary to tertiary health care across the world, developing novel integration strategies, and taking a life span approach.

The health care system can interface more effectively with social services, helping to address social isolation and loneliness, which are linked to an increased risk of mortality, depression, and cognitive decline. Novel strategies to identify, prevent, and mitigate these health consequences are needed across the life span, especially for underserved and minority populations.

With an increasingly aged population, more robust medical, social, and brain health services will be urgently needed. Furthermore, enhanced infrastructure is needed to ensure that caregivers are informed, engaged, available, and have the support they need. By developing and implementing preventative brain health strategies from birth, these challenges will be mitigated later in the life span.

It is necessary to fund research into the brain effects of a new information ecosystem marked by false media and misinformation and develop strategies to identify, prevent, and mitigate effects of misinformation consumption.

Transportation and infrastructure help shape the environments people live in and determine how people get from place to place. There is an opportunity to ensure that these policies and systems help promote healthy lifestyle choices; mitigate air pollution; and ensure access to healthy foods, primary care, and stable jobs that pay a living wage. 
Table 2 (continued)

\begin{tabular}{ll}
\hline Policy area & Opportunity with the Brain Capital Grand Strategy \\
\hline Telecommunications & $\begin{array}{l}\text { Develop ways to increase equitable educational engagement and attainment to improve brain health. } \\
\text { Innovative strategies are especially needed to rethink aging and promote learning and engagement across the }\end{array}$ \\
life span, beginning in early childhood. & Help improve brain function and mental well-being by developing more meaningful ways of digitally \\
connecting and communicating and preventing the adverse health and psychological effects of digital media. & Age limits on social media use should be enforced. \\
Develop bi-directional value of mental health technology transfer to address issues both on earth and in \\
space. Mental health challenges associated with long-duration spaceflights (such as a Mars mission) result \\
from prolonged confinement, microgravity, and different sunlight exposure lengths. Increased dialogue and \\
training opportunities for using these technologies on earth and in space will enhance innovation and \\
outcomes. \\
Develop a new type of Visa program for Global Impact Brain Movement (GIBM) by supporting a \\
community of impact entrepreneurs, investors, and changemakers to build meaningful solutions to advance \\
Brain Capital. The GIBM provides individual pioneering entrepreneurs and investors with a 3-year visa to \\
create, support, and incubate ventures and models that result in positive global impact in terms of Brain \\
Capital policies and investments. After 3 years, migrants can qualify for permanent residency. \\
Criminal justice policymakers, locally and globally, struggle to develop and implement policies to balance \\
justice, punishment, and rehabilitation. However, many of the issues that criminal justice policy is tasked to \\
manage involve the interactions of people and the modification of behavior. Neuroscience researchers are \\
actively mapping circuits and the changes involved in addiction, violence, and mental illness. They are \\
developing neurological devices to help those suffering from mental illness or substance use disorders when \\
traditional pharmaceutical therapeutic methods do not work.
\end{tabular}

billion for a portfolio of 64 projects, according to Lo et al. [52]), a public-private partnership will be necessary for a megafund to have its full impact on building Brain Capital.

\section{The Global Brain Health Institute (GBHI)}

GBHI is a leader in the global community dedicated to protecting the world's aging populations from threats to brain health [53]. GBHI seeks to mentor and train a global community of brain health leaders through the Atlantic Fellows for Equity in Brain Health program. Funded by the Atlantic Philanthropies and based at the UCSF and Trinity College Dublin in Ireland, the GBHI works to improve brain health around the world and train and support a new generation of leaders. Atlantic Fellows at GBHI involve a diverse array of professions and disciplines including medicine, law, business, social science, journalism, and the arts (since 2015, 117 fellows have been trained from 37 countries). The program has funded 65 pilot projects and several Atlantic Fellows have been awarded more than \$17 million to implement programs, fund projects, and conduct research in their home regions. This program supports regional brain health initiatives, such as the Latin American Brain Health Institute at Chile's Universidad Adolfo Ibanez (to be launched in 2021); or the Multi-Partner Consortium to Expand Dementia Research in Latin America (ReDLat, with an investment of $>\$ 7.5$ million). The ReDLat will identify the genetic and socioeconomic/social determinants of health (SES/SDH) risks of neurodegeneration in Latin
America and USA. The cohort involves $>4000$ participants from Latin America (Argentina, Chile, Colombia, Brazil, Mexico, Peru) and a US team (UCSF). The basic outcomes are: (1) genetic contributions to dementia; (2) impact of SES/SDH on clinical-cognitive-neuroimaging signatures; (3) machine-learning differentiation of genetic and SES/ SDH risks in Latin America vs. USA. This 5-year project fosters synergy and harmonization to assess underserved dementia populations. UCSF-LAC collaborations are promoted by providing the following: locally unavailable funding in LAC; scientific and clinical training; LMIC-HIC associations; support for $\mathrm{PhD} /$ postdocs/Fellows; freely shared materials and analysis pipelines. ReDLat brings underrepresented populations to extend existing datasets with novel measures supporting future treatments.

These initiatives illustrate diverse financing mechanisms leading to innovative uses of funding. Furthermore, they impute a broader context for investments beyond public and philanthropic funds, such as business investments that imply a return on investment. These funding structures also mitigate financial risks for governments, attract the participation of new parties in brain health initiatives, increase innovation, and often provide ways to test approaches that will inform future government policies and funding incentives. There are plans for Brain Capital to be represented on the tangible asset side of corporate balance sheets, as opposed to the intangible asset side, however, this work is still in the modeling stage. For further details please see the recent White Paper on the 
Human Capital Accounting Framework [54]. If secured widely, this would dramatically change the corporate benefits of supporting Brain Capital.

\section{Embedding Brain Capital in all policies}

Brain Capital requires wider-ranging policy measures from an in-all-policies approach, broadening considerations beyond all sectors and sciences, using evidence-based interventions, articulating existing policy initiatives from multiple government agencies, and advocating for the importance of long-term investment in the development of cognitive, social, and emotional skills throughout the stages of life. Neurosciences and Behavioral Sciences can collaborate in the design of effective policies and interventions to solve problems related to health, education, poverty, justice, citizen behavior, care for the environment, savings, and other relevant areas of society. Health in All Policies (HiAP) is a predicate for promoting population health and well-being by systematically initiating and facilitating action within different non-health public policy areas $[55,56]$ and recognizes and attempts to address the impact of social determinants of health and illness. Given that brain health is greatly shaped by the social, economic, physical, and cultural environments in which people live, work, and play, effective interventions will require an HiAP approach-reframing health as a crosssectorial issue for all parts of government [35, 55, 56]. HiAP approaches have been developed in mental health [56] and dementia prevention [57]. Table 2 highlights key values of a Brain Capital in-all-policies approach.

\section{Toward a Brain Capital Index}

The central components of Brain Capital need to be formalized and developed into an investment plan. Since one cannot manage what one does not measure, developing a Brain Capital Index (BCI) to track the progress of this approach is critical.

If such an index were investable-as in the case of a mutual fund or exchange-traded fund-it would encourage investment in the entire space by opening it to the passive investor. Index-tracking funds have recently passed the $\$ 10$ trillion mark of assets under management globally, surpassing assets under active management for the first time. Attracting even a small fraction of global passive investment using a BCI would transform the Brain Economy as a whole. Consequently, creating a well-defined and easily computed index is a key part of the Brain Capital Grand Strategy.

In this context, the Human Capital Index (HCI) provides a valuable example. The $\mathrm{HCI}$ is a tool that quantifies the contribution of health and education to the productivity of a country's next generation of workers [58, 59]. Through the HCI, countries can "access how much income they are foregoing because of human capital gaps, and how much faster they can turn these losses into gains if they act now" [58]. Ultimately, HCI and the proposed BCI will enable public and private entities (e.g., governments and corporations) to objectively measure commonly overlooked indicators that fundamentally underpin overall social and economic development and monitor outcomes over time. Table 3 shows other models that can inform a BCI.

There are a range of potential components of the BCI (Fig. 2). Health-related metrics may include incidence and prevalence metrics, access to care, and relapse rates. As we move toward a Brain Economy, educational attainment may be helpful to approximate the Brain Skills of individuals. The output of value-adding novel products and services may help assess innovation outputs. Co-benefits of large-scale initiatives should be captured to understand tax revenue, IP, and employment benefits of such work. There are is also potential for digital metrics to be captured as we outline below.

\section{Brain imaging and digital biomarkers could contribute to the Brain Capital Index}

The components of the BCI are not yet determined, but recent developments may provide quantitative methods of doing so including neuroimaging and digital biomarkers. A global example of applied neuroscience relevant to Brain Capital is the Enhancing Neuroimaging Genetics through Meta-Analysis (ENIGMA) Consortium that includes research groups across more than 40 countries and identified brain metrics in structure and function from magnetic resonance imaging that are associated with a wide range of neurological and psychiatric conditions [60]. In addition to imaging metrics, the ENIGMA Consortium has identified associated genetic, environmental, demographic, cognitive, and psychosocial factors involved in clinical syndromes. Advances by ENIGMA along with many other longitudinal imaging studies help monitor brain health status and provide objective metrics to help quantify Brain Capital.

Identification and validation of digital biomarkers is beginning to move into mainstream. Behavioral measures such as patterns of interaction on smartphone devices, may help provide a continuous indication of mood and cognition to support diagnosis, prognosis, and treatment monitoring for different neurological and psychiatric conditions [61].

Digital biomarker-based surveillance tools are becoming increasingly ubiquitous and provide a noninvasive and highly granular approach to assessing mood, cognition, activity, and other biometrics. Ultimately, digital biomarkers may provide 


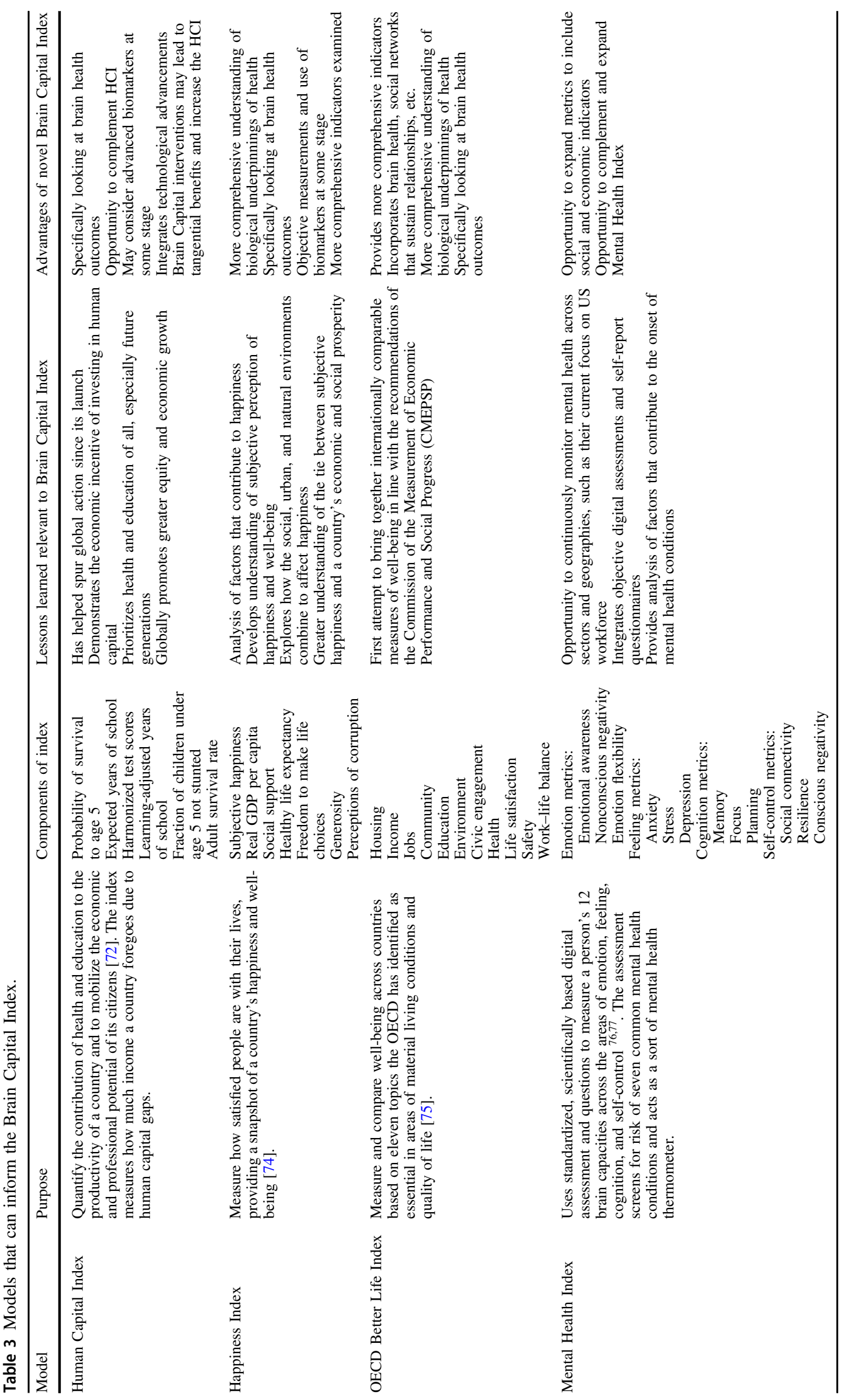




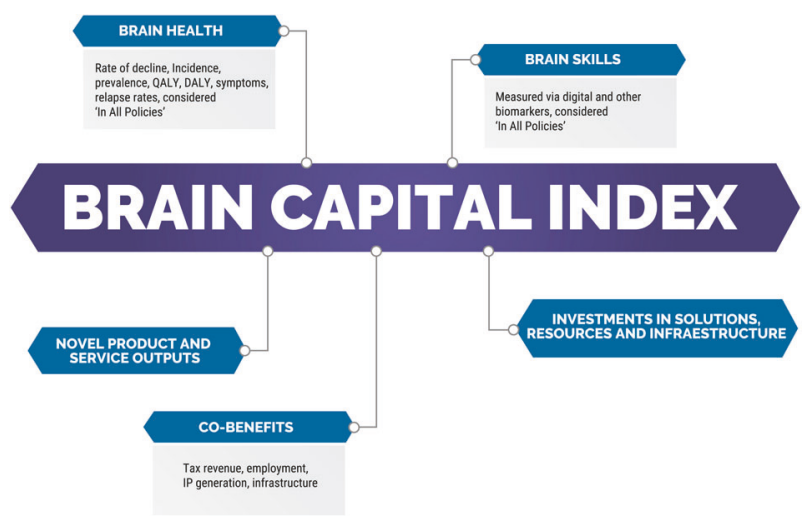

Fig. 2 Potential components of the Brain Capital Index. QALY quality-adjusted life year, DALY disability-adjusted life year.

more comprehensive insights and thus supplement an increasingly hybrid model of care that integrates insights from technology and clinicians [62]. For example, mental health status (including specific disorders and related symptomology) can be captured and studied using behavioral and linguistic cues from social media data [63, 64]. Mental health condition data tracked from digital cohorts via social media correlate with statistics obtained through traditional methodologies, suggesting that this approach may be a promising complement to current epidemiological practices [64]. Artificial intelligence techniques of real time surveillance of digital medical records, for example, have proven to be superior to clinician assessments of suicide risk using structured instruments $[65,66]$. Indeed, sensitivity and specificity permitting, digital surveillance tools enhanced by artificial intelligence may usher in a new era of more responsive and deliberate public health interventions allowing experts to track the progress or the effects of targeted interventions in near real time [64, 67].

Regardless of biomarker type, a careful process of translation is required to ensure they are implemented effectively. For example, the working steps of translational psychiatry as outlined by Licinio and Wong [68] include, in a one-way direction: (T0) discovery (via preclinical, clinical, and epidemiological science), (T1) bench to bedside, (T2) bedside to clinical applications (clinical trials), (T3) translation to policy and health care guidelines, (T4) assessment of health policy and usage, and (T5) global health applications.

\section{Responsible innovation in Support of Brain Capital Innovation}

Technology may well drive the future of public health surveillance by helping to collect and integrate disparate sources of information and track and quantify the outcomes of Brain Capital interventions.
Digital surveillance tools will be a core component of the transition to precision public health [69]. Digital surveillance tools can include mobile apps and link to diverse national datasets. Although biomarkers may be incorporated into a BCI, extreme caution and ethical considerations must be taken [70]. Extensive measures will be needed to mitigate the potential downsides of these new technologies, including education disparities, appropriate policies, risk management, systems design, research, and regulatory frameworks [69].

Responsible innovation is an increasingly prominent framework and is especially critical [71]. A recent OECD Recommendation on Responsible Innovation in Neurotechnology proposed the first international standard in this domain [72]. It "aims to guide governments and innovators to anticipate and address the ethical, legal and social challenges raised by novel neurotechnologies while promoting innovation in the field." It articulates "the importance of (1) high-level values such as stewardship, trust, safety, and privacy in this technological context, (2) building the capacity of key institutions like foresight, oversight and advice bodies, and (3) processes of societal deliberation, inclusive innovation, and collaboration." These principles can be usefully adapted to guide the development and implementation of novel technologies for Brain Capital.

\section{Workforce development supporting a Brain Capital Grand Strategy}

Brain health diplomacy is a model that aims to optimally shape global policy, transcend disciplines, and marshal resources at a sufficient scale to improve national and global brain health outcomes. This model builds on several existing theoretical frameworks including health diplomacy, science diplomacy, and innovation diplomacy. Brain health diplomacy seeks to protect the world's populations from the variable threats to brain health throughout the life span but with particular attention paid to late life; to train and connect the next generation of brain health leaders; to collaborate in expanding preventive measures and treatments; to transfer knowledge; and to carry out advocacy. Key examples of brain health diplomacy include the GBHI, the Concussion Legacy Foundation, HBGI, One Mind, European Brain Council, Alzheimer's Association, and Alzheimer's Disease International. Adapted from the NESTA Innovation Policy Toolkit [73], we elucidated roles relevant to Brain Health Diplomats including "Exploring and Assessing," "Influencing and Promoting," "Cultivating and Connecting," "Advocating and Supporting," and "Activating and Scaling" [74].

Robust, transdisciplinary brain health education is critical to support the Brain Capital strategy. The Brainstorm Lab for Mental Health Innovation provides an example of such 
education [75]. It is housed within Stanford University School of Medicine's Department of Psychiatry and collaborates with the Schools of Business and Engineering. The Brainstorm Lab has developed two innovative courses for undergraduate and graduate students: PSYC 240: Designing for the 2 Billion: Leading Innovation in Mental Health and PSYC 242: Mental Health Innovation Studio: Entrepreneurship, Technology and Policy [75].

\section{Conclusion}

The time is now to catalyze a Grand Strategy. Brain Capital can be a key component in shaping economic resiliencelinked to our digitalized, globalized, complex, and interconnected yet fragile global economy. Brain Capital resonates with existing efforts and helps build long-term global economic recovery that promotes brain health and brain skills helping address urgent challenges caused and exacerbated by COVID. Current policies, concepts and economic measures neither account for the neuroscientific drivers of productivity nor the increasingly brain skillsfocused workforce demands of the twenty-first century. Furthermore, current approaches are insufficient to combat the rising complexity of challenges brought about by COVID. The preservation and development of Brain Capital positively impacts educational, social, health, institutional, and economic dimensions at the individual and collective level. Hence, it should be considered a strategic resource for a country, corporations, and public policies in a brain-based world. A system that fosters collaboration among all Brain Capital stakeholders and practitioners, including economists, philanthropists, financiers, governments, public health experts, consumers, entrepreneurs, and neuroscientists, is needed. It is the intersection and fusion of these disciplines where unexpected advances will arise [21]. Brain Capital harnesses transdisciplinary development and innovation and entrepreneurship [21]. Our current reality demands innovation and action across all levels, sectors, and systems of society and the collective world; brain health will act as the underlying nutrient and catalysis for progress. We recommend an action taskforce be established to further articulate and implement Brain Capital.

Acknowledgements We would like to thank the following individuals for their helpful inputs to this concept and paper: Vikram Patel, Maureen Hackett, Jim Hackett, Bruce Miller, Ian Everall, Jeremy Kranz, Jeff Paine, Mark Heinemeyer, Chase Untermeyer, and Thomas Dougherty.

Funding KS is supported by NIMH, Training the Science of Child Mental Health Treatment, 5T32MH073517-14. MB is supported by a NHMRC Senior Principal Research Fellowship (1059660 and 1156072). JC is supported by KMA; NIGMS grant P20GM109025; NINDS grant U01NS093334; and NIA grant R01AG053798. No other co-authors have funding support to note. AWL gratefully acknowledges funding support from Jean-Jacques DeGroof and other sponsors of the MIT Laboratory for Financial Engineering (https://lfe. mit.edu/about/sponsors/). No funding bodies of AWL had any role in study design, data collection and analysis, decision to publish, or preparation of this paper. No direct funding was received for this study by AWL, who was personally salaried by his institution during the period of writing (though no specific salary was set aside for or given to AWL for the writing of this paper). DJ's work was supported, in part, by the National Institute of Mental Health R01 grant (R01MH094151-01 to DJ [PI]), and the Sam and Rose Stein Institute for Research on Aging at the University of California San Diego. WDD reports funding from GBHI ALZ UK-20-640170 and from Oregon Health Authority. HL receives grant funding from NIMH, NIA, NCCIH, NIAMS, PCORI, Alzheimer's Research and Prevention Foundation. E. Storch reports research support from NIH, Texas Higher Education Coordinating Board, Red Cross, Greater Houston Community Foundation, ReBuild Texas. AI is partially supported by grants from CONICET, ANID/FONDAP/15150012, the Interamerican Development Bank (IDB), GBHI ALZ UK-20-639295, and the Multipartner Consortium to Expand Dementia Research in Latin America (ReDLat; NIH NIA R01 AG057234, Alzheimer's Association SG-20725707, Tau Consortium, and Global Brain Health Institute).

\section{Compliance with ethical standards}

Conflict of interest JC has provided consultation to Acadia, Actinogen, Alkahest, Alzheon, AnnovisBio, Avanir, Axsome, BiOasis, Biogen, Cassava, Cerecin, Cortexyme, Cytox, Diadem, EIP Pharma, Eisai, Foresight, GemVax, Genentech, Green Valley, Grifols, Maplight, Merck, Otsuka, Resverlogix, Roche, Samumed, Samus, Signant, Third Rock, and United Neuroscience pharmaceutical and assessment companies. JC has stock options in ADAMAS, MedAvante, QR pharma/AnnovisBio, BiOasis. Ryan Abbott works as an attorney and consult to a variety of commercial enterprises in the life science and information technology fields. AWL reports personal investments in public and private biotech companies, biotech venture capital funds, and biotech mutual funds. He is a director of BridgeBio Pharma and Roivant Sciences, and a member of the Board of Overseers at Beth Israel Deaconess Medical Center and the NIH's National Center for Advancing Translational Sciences Advisory Council and Cures Acceleration Network Review Board. He is a co-founder and partner of QLS Advisors, a health care analytics company; an advisor to BrightEdge Ventures, the impact fund of the American Cancer Society; and chairman emeritus and senior advisor to AlphaSimplex Group, an asset management company he founded in 1999. CR receives a stipend from the American Association for Geriatric Psychiatry for editing the American Journal of Geriatric Psychiatry; royalty income from the University of Pittsburgh as co-inventor of the Pittsburgh Sleep Quality Inventory. IT reports income and stock in ALTOIDA LLC and has a patent "Apparatus, method and program for determining a cognitive state of a user of a mobile device" pending. HAE receives fees from PRODEO LLC, PreActive Technologies INC and ALTOIDA LLC. CHN had served as a consultant for Lundbeck, Grunbiotics, Servier, Janssen-Cilag, and Eli Lilly, received research grant support from Lundbeck, and speaker honoraria from Servier, Lundbeck, Bristol-Myers Squibb, Organon, Eli Lilly, GlaxoSmithKline, Janssen-Cilag, Astra-Zenaca, Wyeth, and Pfizer. WDD reports personal fees from Commonwealth Fund, personal fees from AARP, personal fees from Insights to Illuminate, LLC, personal fees from Cognitive Solutions, LLC, personal fees from Oregon Health Care Association, personal fees from Mather LifeWays, personal fees from Splaine Consulting, outside the submitted work. E. Storch reports consulting fees from Levo Therapeutics; Honoraria from International OCD Foundation; and book royalties from Wiley, Elsevier, Springer, American Psychological Association, Oxford, Jessica Kingsley, 
Lawrence Erlbaum. The contents of this publication are solely the responsibility of the authors and do not represent the official views of these Institutions. No other co-authors have disclosures.

Publisher's note Springer Nature remains neutral with regard to jurisdictional claims in published maps and institutional affiliations.

\section{References}

1. Lund S, Manyika J, Segel LH, Dua A, Hancock B, Rutherford S, et al. The future of work in America: people and places, today and tomorrow. Washington, DC: McKinsey Global Institute; 2019. https://www.mckinsey.com/featured-insights/future-of-work/thefuture-of-work-in-america-people-and-places-today-and-tomorrow.

2. OECD NAEC. A systemic resilience approach to dealing with Covid-19 and future shocks. http://www.oecd.org/coronavirus/ policy-responses/a-systemic-resilience-approach-to-dealing-withcovid-19-and-future-shocks-36a5bdfb/ (2020). Accessed 2020.

3. Dash P, Dorling G, Rutter K-A, Linzer K, Ramdorai A, Remes J, et al. How prioritizing health could help rebuild economies. https://www.mckinsey.com/industries/healthcare-systems-andservices/our-insights/how-prioritizing-health-could-help-rebuildeconomies?cid $=$ other-eml-alt-mgi-mck\&hlkid $=\mathrm{e} 9526 \mathrm{e} 2 \mathrm{a}$ 6246477 bbe55addf554e18c0\&hctky $=12203802 \&$ hdpid $=$ 1f9c67f8-fc5f-4357-b3fd-c4ed217bbfc6 (2020). Accessed 2020.

4. Chisholm D, Sweeny K, Sheehan P, Rasmussen B, Smit F, Cuijpers $\mathrm{P}$, et al. Scaling-up treatment of depression and anxiety: a global return on investment analysis. Lancet Psychiatry. 2016;3:415-24.

5. Holmes EA, O'Connor RC, Perry VH, Tracey I, Wessely S, Arseneault L, et al. Multidisciplinary research priorities for the COVID-19 pandemic: a call for action for mental health science. Lancet Psychiatry. 2020;7:547-60.

6. Blazer D. Social isolation and loneliness in older adults-a mental health/public health challenge. JAMA Psychiatry. 2020;77:990-1.

7. Vahia IV. COVID-19, aging and mental health: lessons from the first six months. Am J Geriatr Psychiatry. 2020;28:691-4.

8. Orben A, Tomova L, Blakemore S-J. The effects of social deprivation on adolescent development and mental health. Lancet Child Adholesc Health. 2020;4:P634-40.

9. Steenblock C, Todorov V, Kanczkowski W, Eisenhofer G, Schedl A, Wong ML, et al. Severe acute respiratory syndrome coronavirus 2 (SARS-CoV-2) and the neuroendocrine stress axis. Mol Psychiatry. 2020;25:1611-7.

10. Milner A, King TL, LaMontagne AD, Aitken Z, Petrie D, Kavanagh AM. Underemployment and its impacts on mental health among those with disabilities: evidence from the HILDA cohort. J Epidemiol Community Health. 2017;71:1198-202.

11. Koralnik IJ, Tyler KL. COVID-19: a global threat to the nervous system. Ann Neurol. 2020;88:1-11.

12. Varatharaj A, Thomas N, Ellul MA, Davies NWS, Pollak T, Tenorio E, et al. Neurological and neuropsychiatric complications of COVID-19 in 153 patients: a UK-wide surveillance study. Lancet Psychiatry. 2020;7:P875-82.

13. Mak IW, Chu CM, Pan PC, Yiu MG, Chan VL. Long-term psychiatric morbidities among SARS survivors. Gen Hosp Psychiatry. 2009;31:318-26.

14. Abbott R. The reasonable robot: artificial intelligence and the law. London: Cambridge University Press; 2020. https://doi.org/10. 1017/9781108631761.

15. Bavel JJV, Baicker K, Boggio PS, Capraro V, Cichocka A, Cikara $\mathrm{M}$, et al. Using social and behavioural science to support COVID19 pandemic response. Nat Hum Behav. 2020;4:460-71.
16. Wilson M, Wilkerson B. Brain health + brain skills = brain capital: final report of the global business and economic roundtable on addiction and mental health. Toronto, Ontario: Mental Health International; 2011. http://www.mentalhealthroundtable. ca/report/MHR_FinalReport.pdf.

17. Ibáñez A, Sedeño L, García AM. Neuroscience and social science: the missing link. Switzerland: Springer; 2017. https://doi.org/10. 1007/978-3-319-68421-5.

18. Ibáñez A, García AM. Contextual cognition: the sensus communis of a situated mind. Switzerland: Springer; 2018. https://doi.org/10. 1007/978-3-319-77285-1.

19. Ibanez A, Kotz SA, Barrett L, Moll J, Ruz M. Situated affective and social neuroscience. Front Hum Neurosci. 2014;8:547.

20. Cosmelli D, Ibáñez A. Human cognition in context: on the biologic, cognitive and social reconsideration of meaning as making sense of action. Integr Psychol Behav Sci. 2008;42:233.

21. Smith E, Au R, Mosse M, Lavretsky H, Forbes M, Eyre HA. Rebooting late-life mental health innovation and entrepreneurship with convergence science. Am J Geriatr Psychiatry. 2020;28:591-6.

22. Beddington J, Cooper CL, Field J, Goswami U, Huppert FA, Jenkins $R$, et al. The mental wealth of nations. Nature. 2008;455:1057-60.

23. Lim SS, Updike RL, Kaldjian AS, Barber RM, Cowling K, York $\mathrm{H}$, et al. Measuring human capital: a systematic analysis of 195 countries and territories, 1990-2016. Lancet. 2018;392:1217-34.

24. Flores EC, Fuhr DC, Bayer AM, Lescano AG, Thorogood N, Simms V. Mental health impact of social capital interventions: a systematic review. Soc Psychiatry Psychiatr Epidemiol. 2018;53:107-19.

25. Luthans F, Youssef-Morgan CM. Psychological capital: an evidence-based positive approach. Annu Rev Organ Psychol Organ Behav. 2017;4:339-66.

26. Song R, Sun N, Song X. The efficacy of psychological capital intervention (PCI) for depression from the perspective of positive psychology: a pilot study. Front Psychol. 2019;10:1816.

27. The World Bank. Human Capital Project. 2020. https://www. worldbank.org/en/publication/human-capital.

28. World Bank. Building human capital starts with health. 2018. World Bank Blogs. Accessed: 17 Oct 2020. https://blogs.worldba nk.org/health/building-human-capital-starts-health.

29. Vigo DV, Patel V, Becker A, Bloom D, Yip W, Raviola G, et al. A partnership for transforming mental health globally. Lancet Psychiatry. 2019;6:350-6.

30. McPherson KE, Kerr S, McGee E, Morgan A, Cheater FM, McLean J, et al. The association between social capital and mental health and behavioural problems in children and adolescents: an integrative systematic review. BMC Psychol. 2014;2:7.

31. Santamaría-García H, Baez S, Gómez C, Rodríguez-Villagra $\mathrm{O}$, Huepe D, Portela M, et al. The role of social cognition skills and social determinants of health in predicting symptoms of mental illness. Transl Psychiatry. 2020;10:165.

32. Campbell C. Social capital, social movements and global public health: fighting for health-enabling contexts in marginalised settings. Soc Sci Med. 2019;257:112153.

33. Luthans $F$. The need for and meaning of positive organizational behavior. J Organ Behav. 2002;23:695-706.

34. Richards M, Deary I. Cognitive capital in the British birth cohorts: an introduction. Longitud Life Course Stud. 2010;1:197-200.

35. Chapman SB, Cook LG, Vas AK, Robertson IH. Enhancing human cognitive capital by harnessing the brain's inherent neuroplasticity. In: Schnyer MDMaDM, editor. Human performance optimization: the science and ethics of enhancing human capabilities. New York City: Oxford University Press; 2012.

36. Magnuson K, Schindler H. Supporting children's early development by building caregivers' capacities and skills: a theoretical approach informed by new neuroscience research. J Fam Theory Rev. 2019;11:59-78. 
37. Pollak S, Wolfe B, Barbara L. How developmental neuroscience can help address the problem of child poverty (March 2020). NBER Working Paper No. w26842. 2020. https://ssrn.com/abstra $\mathrm{ct}=3550991$.

38. Manes F. 7 How neuroscience can inform public policy. J Neurol Neurosurg Psychiatry. 2019;90:A3-4.

39. Healthy brain bonds : is this a feasible option (English). WBG Global Mental Health Initiative Washington, D.C.: World Bank Group; 2018. http://documents.worldbank.org/curated/en/310661533223406666/ Healthy-brain-bonds-is-this-a-feasible-option.

40. Weill Neurohub. https://www.weillneurohub.org/ (2020). Accessed 2020.

41. Healthy Brains Global Initiative. https://onemind.org/healthy-bra ins-global-initiative/ (2020). Accessed 2020.

42. CIRM California's Stem Cell Agency. 2020. https://www.cirm.ca. gov/.

43. Wei D, Rose A. Economic impacts of the California Institute for Regenerative Medicine (CIRM): Schaeffer Center for Health Policy and Economics Sol Price School of Public Policy University of Southern California; 2019. https://www.cirm.ca.gov/sites/default/ files/CIRM_Economic\%20Impact\%20Report_10_3_19.pdf.

44. Fundacion INECO. Institute of Neurosciences and Public Policies. 2020. https://www.fundacionineco.org/en/institutos/instituto-deneurociencias-y-politicas-publica/.

45. Iovan S, Lantz PM, Shapiro S. "Pay for success" projects: financing interventions that address social determinants of health in 20 countries. Am J Public Health. 2018;108:1473-7.

46. Nonprofit Finance Fund. Pay for Success: The First 25. https://nff. org/report/pay-success-first-25 (2019). Accessed 2019.

47. Social FInance. Career Impact Bonds. https://socialfinance.org/ca reer-impact-bonds/ (2020). Accessed 2020.

48. Center for BrainHealth. The BrainHealth Project. https://bra inhealth.utdallas.edu/the-brainhealth-project/ (2020). Accessed 2020.

49. Alzheimer's Drug Discovery Foundation. https://www.alzdiscovery. org/about-addf (2020). Accessed 2020.

50. Idrus AA. Dementia Discovery Fund reels in $\$ 350 \mathrm{M}$ for diseasemodifying drugs. FierceBiotech. 2018. https://www.fiercebiotech. com/dementia-discovery-fund-reels-350m-for-disease-modifyingdrugs. Accessed 17 Oct 2020.

51. Fernandez J-M, Stein RM, Lo AW. Commercializing biomedical research through securitization techniques. Nat Biotechnol. 2012; 30:964-75.

52. Lo AW, Ho C, Cummings J, Kosik KS. Parallel discovery of Alzheimer's therapeutics. Sci Transl Med. 2014;6:241cm245.

53. Smith D. The next generation of leaders advocating for brain health. Lancet Neurol. 2018;17:29-30.

54. WEF. Human capital as an asset: an accounting framework to reset the value of talent in the new world of work. http://www3. weforum.org/docs/WEF_NES_HR4.0_Accounting_2020.pdf (2020). Accessed 2020.

55. Wernham A, Teutsch SM. Health in All Policies for big cities. J Public Health Manag Pract. 2015;21 Suppl 1:S56-65.

56. Joint action on mental health and well-being: mental Health in All Policies. 2017. European Union. Accessed: 17 Oct 2020. https://www.lisboninstitutegmh.org/assets/docs/publications/ MENTAL\%20HEALTH\%20IN\%20ALL\%20POLICIES20200612000831.pdf.

57. Olivari BS, French ME, McGuire LC. The Public Health Road Map to respond to the growing dementia crisis. Innov Aging. 2020;4:1-11.
58. The World Bank. About The Human Capital Project. 2020. https://www.worldbank.org/en/publication/human-capital/brief/a bout-hep.

59. World Bank Blogs. How is the Human Capital Index prompting action? https://blogs.worldbank.org/voices/how-human-capitalindex-prompting-action (2019). Accessed 2019.

60. Thompson PM, Jahanshad N, Ching CR, Salminen LE, Thomopoulos SI, Bright J, et al. ENIGMA and global neuroscience: a decade of large-scale studies of the brain in health and disease across more than 40 countries. Transl Psychiatry. 2020;10:1-28.

61. Dagum P. Digital biomarkers of cognitive function. NPJ Digit Med. 2018;1:1-3.

62. Torous J, Myrick KJ, Rauseo-Ricupero N, Firth J. Digital mental health and COVID-19: using technology today to accelerate the curve on access and quality tomorrow. JMIR Ment Health. 2020;7: e18848.

63. Chancellor S, De Choudhury M. Methods in predictive techniques for mental health status on social media: a critical review. NPJ Digit Med. 2020;3:1-11.

64. Amir S, Dredze M, Ayers JW. Mental health surveillance over social media with digital cohorts. In: Proceedings of the sixth workshop on computational linguistics and clinical psychology. Minneapolis, Minnesota: Association for Computational Linguistics; 2019.

65. Tran T, Luo W, Phung D, Harvey R, Berk M, Kennedy RL, et al. Risk stratification using data from electronic medical records better predicts suicide risks than clinician assessments. BMC Psychiatry. 2014;14:76.

66. Karmakar C, Luo W, Tran T, Berk M, Venkatesh S. Predicting risk of suicide attempt using history of physical illnesses from electronic medical records. JMIR Ment Health. 2016;3:e19.

67. Samerski S. Individuals on alert: digital epidemiology and the individualization of surveillance. Life Sci Soc Policy. 2018;14:13.

68. Licinio J, Wong ML. Launching the 'war on mental illness'. Mol Psychiatry. 2014;19:1-5.

69. Weeramanthri TS, Dawkins HJS, Baynam G, Bellgard M, Gudes O, Semmens JB. Editorial: precision public health. Front Public Health. 2018;6:1-3.

70. Cosgrove V, Gliddon E, Berk L, Grimm D, Lauder S, Dodd S, et al. Online ethics: where will the interface of mental health and the internet lead us? Int J bipolar Disord. 2017;5:26.

71. Eyre HA, Ellsworth W, Fu E, Manji H, Berk M. Responsible innovation in technology for mental health care. Lancet Psychiatry. 2020;7:728-30. https://doi.org/10.1016/S2215-0366(20)30192-9.

72. OECD. Recommendation of the Council on Responsible Innovation in Neurotechnology. Paris, France: OECD; 2020. https://www.oecd.org/science/recommendation-on-responsibleinnovation-in-neurotechnology.htm.

73. Nesta. Innovation Policy Toolkit: introduction to innovation policy and collaboration. https://www.nesta.org.uk/toolkit/innova tion-policy-toolkit-introduction-to-innovation-policy-and-colla boration/ (2015). Accessed 2015.

74. Ternes K, Iyengar V, Lavretsky H, Dawson WD, Booi L, Ibanez A, et al. Brain health INnovation Diplomacy: a model binding diverse disciplines to manage the promise and perils of technological innovation. Int Psychogeriatr. 2020;32:955-79. https://doi. org/10.1017/S1041610219002266.

75. Jain A. Stanford Brainstorm presents America's first mental health innovation course. Harv Technol Rev. 2020;3. https://harva rdtechnologyreview.com/2020/03/30/stanford-brainstorm-presents-a mericas-first-mental-health-innovation-course/. 


\section{Affiliations}

Erin Smith ${ }^{1} \cdot$ Diab Ali ${ }^{2,3} \cdot$ Bill Wilkerson ${ }^{4} \cdot$ Walter D. Dawson $\mathbb{1}^{5,6,7,8} \cdot$ Kunmi Sobowale $^{9} \cdot$ Charles Reynolds $\mathrm{II}^{10}$. Michael Berk ${ }^{11,12,13,14}$ • Helen Lavretsky ${ }^{9}$ - Dilip Jeste ${ }^{15}$. Chee H. $\mathrm{Ng}^{16} \cdot$ Jair C. Soares ${ }^{17} \cdot$ Gowri Aragam $^{18}$. Zoe Wainer $^{19}$ • Husseini K. Manji ${ }^{20,21}$ - Julio Licinio ${ }^{22}$ - Andrew W. Lo ${ }^{23}$ - Eric Storch ${ }^{24}$ - Ernestine Fu ${ }^{1}$. Marion Leboyer ${ }^{25} \cdot$ loannis Tarnanas $\mathbb{D}^{7,8} \cdot$ Agustin Ibanez $\mathbb{D}^{7,8,26,27,28,29} \cdot$ Facundo Manes $^{27,30}$. Sarah Caddick ${ }^{31}$. Howard Fillit ${ }^{32}$ - Ryan Abbott ${ }^{9,33}$ - lan H. Robertson ${ }^{7,8,34}$. Sandra B. Chapman ${ }^{34}$ - Rhoda $\mathrm{Au}^{35}$ - Cara M. Altimus ${ }^{36}$. William Hynes $^{37}$ - Patrick Brannelly ${ }^{38}$ - Jeffrey Cummings $s^{39,40} \cdot$ Harris A. Eyre $\mathbb{I}^{11,12,18,41}$

1 Stanford University, Palo Alto, CA, USA

2 School of Medicine, Ochsner Clinical School, New Orleans, LA, USA

3 Faculty of Medicine, University of Queensland, Brisbane, QLD, Australia

4 Mental Health International, Toronto, ON, Canada

5 Department of Neurology, School of Medicine, Oregon Health and Science University, Portland, OR, USA

6 Institute on Aging, College of Urban and Public Affairs, Portland State University, Portland, OR, USA

7 Global Brain Health Institute, Trinity College Dublin, Dublin, Ireland

8 Global Brain Health Institute, University of California, San Francisco, San Francisco, CA, USA

9 Semel Institute for Neuroscience and Human Behavior and Department of Medicine, David Geffen School of Medicine, University of California, Los Angeles, CA, USA

10 Department of Psychiatry, University of Pittsburgh, Pittsburgh, PA, USA

11 Deakin University, IMPACT, The Institute for Mental and Physical Health and Clinical Translation, School of Medicine, Barwon Health, Geelong, VIC, Australia

12 Department of Psychiatry, University of Melbourne, Melbourne, VIC, Australia

13 Orygen Youth Health, University of Melbourne, Melbourne, VIC, Australia

14 The Florey Institute for Neuroscience and Mental Health, University of Melbourne, Melbourne, VIC, Australia

15 Sam and Rose Stein Institute for Research on Aging, University of California, San Diego, San Diego, CA, USA

16 Department of Psychiatry, The Melbourne Clinic and St Vincent's Hospital, University of Melbourne, Richmond, VIC, Australia

17 Center of Excellence on Mood Disorders, Louis Faillace Department of Psychiatry and Behavioral Sciences, UTHealth, Houston, TX, USA

18 Brainstorm Laboratory for Mental Health Innovation, Department of Psychiatry, Stanford University School of Medicine, Palo Alto, CA, USA

19 Department of Genetics, Melbourne Medical School, University of Melbourne, Melbourne, VIC, Australia
20 Neuroscience, Janssen Pharmaceuticals, Johnson \& Johnson, Titusville, NJ, USA

21 Department of Psychiatry and Behavioral Sciences, Duke University School of Medicine, Durham, NC, USA

22 Departments of Psychiatry, Pharmacology, Medicine, and Neuroscience \& Physiology, College of Medicine, SUNY Upstate Medical University, Syracuse, NY, USA

23 Laboratory for Financial Engineering, Department of Finance, Sloan Business School, Massachusetts Institute of Technology, Boston, MA, USA

24 Menninger Department of Psychiatry and Behavioral Sciences, Baylor College of Medicine, Houston, TX, USA

25 Psychiatry Department, University Paris Est Créteil, INSERM U955, FondaMental Foundation, Creteil, France

26 Cognitive Neuroscience Center (CNC), Universidad San Andres, Riobamba 1276, C1116ABJ San Andrés, Buenos Aires, Argentina

27 National Scientific and Technical Research Council (CONICET), Godoy Cruz 2290, Piso 9 (C1425FQB), Buenos Aires, Argentina

28 Center for Social and Cognitive Neuroscience (CSCN), Universidad Adolfo Ibanez, School of Psychology, Adolfo Ibañez University, Av. Presidente Errázuriz 3328, Las Condes, Santiago, Chile

29 Universidad Autónoma del Caribe, Calle 90 \# 46-112, Barranquilla, Atlántico, Colombia

30 Institute of Cognitive and Translational Neuroscience (INCYT), INECO Foundation, Favaloro University, Buenos Aires, Argentina

31 Thalamic, London, UK

32 Departments of Geriatric Medicine, Palliative Care and Neuroscience, The Icahn School of Medicine at Mount Sinai, New York City, NY, USA

33 School of Law, University of Surrey, Guildford, UK

34 Center for BrainHealth, The BrainHealth Project, The University of Texas at Dallas, Dallas, TX, USA

35 Departments of Anatomy, Neurobiology, Neurology and Epidemiology, Boston University Schools of Medicine and Public Health, Boston, MA, USA

36 Center for Strategic Philanthropy, Milken Institute, Washington, DC, USA

37 New Approaches to Economic Challenges Unit, Organisation for Economic Cooperation and Development (OECD), Paris, France 
38 Rainwater Charitable Foundation, Dallas, TX, USA

39 Chambers-Grundy Center for Transformative Neuroscience, Department of Brain Health, School of Integrated Health Sciences, University of Nevada Las Vegas, Las Vegas, NV, USA
40 Cleveland Clinic Lou Ruvo Center for Brain Health, Las Vegas, NV, USA

41 Discipline of Psychiatry, School of Medicine, The University of Adelaide, Adelaide, SA, Australia 